
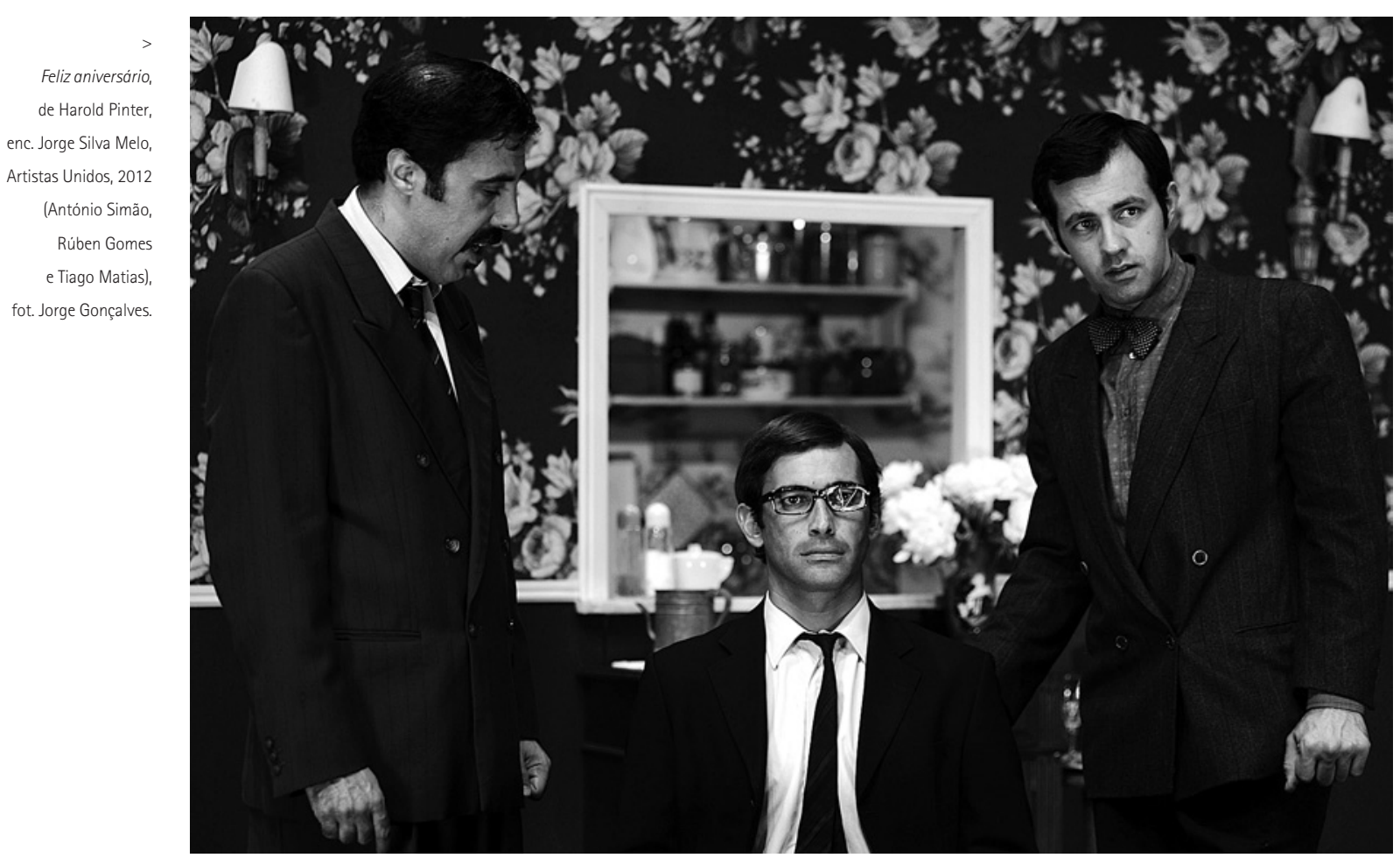

\title{
Eles não têm nada que nos dar ordens
} Emília Costa

Título: Feliz aniversário [The Birthday Party (1958)]. Autor: Harold Pinter. Tradução: Artur Ramos e Jaime Salazar Sampaio. Encenação: Jorge Silva Melo. Cenografia e Figurinos: Rita Lopes Alves. Luz: Pedro Domingos. Interpretação: Alexandra Viveiros, Américo Silva, Andreia Bento, António Simão, Rúben Gomes e Tiago Matias. Produção: Artistas Unidos. Local e data de estreia: Teatro da Politécnica, Lisboa, 05 de Setembro de 2012.

Petey (vencido) Reaja, Stanley. Eles não têm nada que Ihe dar ordens. Harold Pinter (2005: 107)

Feliz aniversário, segunda peça de Harold Pinter, dramaturgo inglês e Nobel da literatura em 2005, estreou no Arts Theatre, em Cambridge, a 28 de Abril de 1958, com encenação de Peter Wood, tendo tido uma boa recepção por parte do público universitário. Porém, quando finalmente, ainda nesse ano, foi representada em Londres, mais precisamente em Hammersmith, no então denominado Lyric Opera House, foi arrasada pela crítica, o que levou ao abandono dos espectadores, e à sua saída de cena ao fim de oito representações. Apesar deste titubeante começo, Feliz aniversário tornou-se numa das peças mais famosas de Harold Pinter, vindo a ser adaptada ao cinema em 1968 pelo realizador norte-americano William Friedkin e, mais tarde, em 1987, à televisão, pela BBC, por Kenneth Ives, tendo como participação de relevo o próprio Harold Pinter no papel de Nat Goldberg.

Já em Portugal viu a sua estreia em Dezembro de 1967 no Teatro Avenida, em Lisboa, pela companhia Amélia Rey Colaço - Robles Monteiro, com encenação de Artur Ramos, e, após três representações, foi abruptamente interrompida, devido a um incêndio que devastou o teatro, vindo a ser reposta, posteriormente, em Abril de 1968. Desde então, e decorridos mais de quarenta anos, apenas o teatro amado GOTA em 1972, os Lisbon Players em 1990 e o colectivo artístico Ninho de Viboras em 2007 terão ousado encenar esta peça.

Finalmente, a companhia Artistas Unidos, ao inaugurar a temporada 2012/2013, fê-lo revisitando Pinter, a quem longamente se dedicara nos anos de 2001 a 2003, e, desta vez, encenando esta primeira peça em três actos de um dos maiores dramaturgos da segunda metade do século $X X$, a quem, infelizmente, não tem sido dada a devida atenção nos palcos portugueses.

Feliz aniversário é uma peça perturbadora, enigmática e, como todo o teatro de Pinter, irresistivel.

0 casal Boles, Petey e Meg, arrendam quartos, visto que a sua casa até vem no guia, mas apenas têm um hóspede, Stanley, um trintão desempregado, antipático e deprimido, que outrora, talvez, tenha sido pianista, e que vegeta naquela pequena vivenda situada numa cidadezinha de província à beira-mar. Meg, a típica dona de casa de uma família inglesa da classe-média baixa, dedica-se ao cuidado da casa, do marido e do hóspede, e, perante a desatenção do marido, desenvolve um sentimento ambíguo 

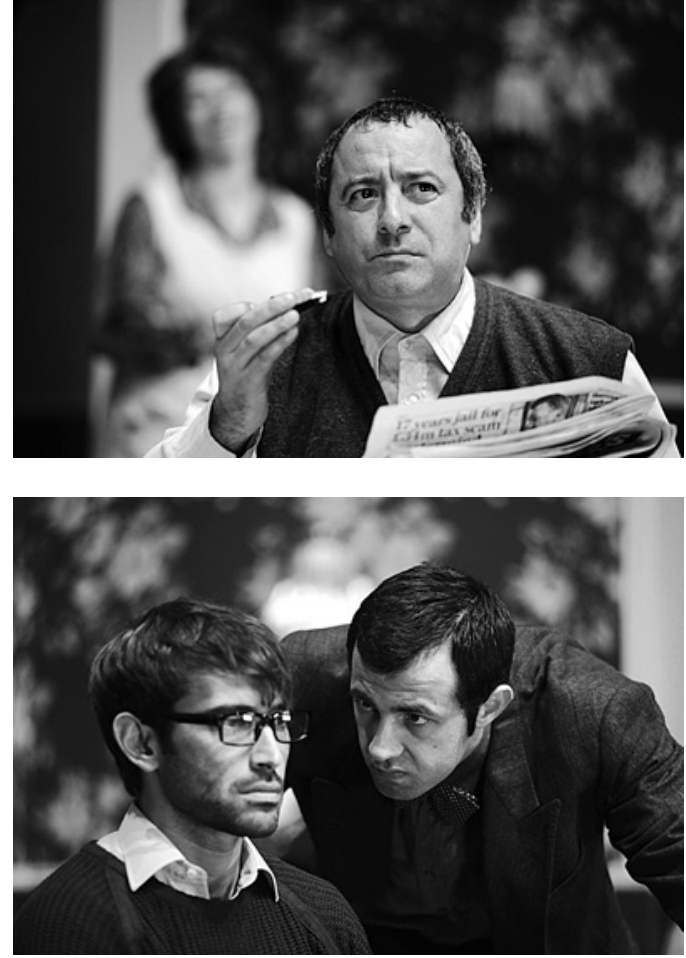

pelo hóspede, mais carnal que maternal, a quem procura tocar e acariciar mas, por quem, é continuamente repelida e verbalmente maltratada. É neste contexto familiar que chegam dois novos hóspedes, Goldberg e McCann, o primeiro, um cinquentão bem-falante e autoritário e o segundo um trintão introvertido e submisso ao primeiro, que vieram, não se sabe como nem porquê, em representação das razões do Estado ou da Religião, ou de ambas, transformar Stanley num homem novo, num elemento útil para a sociedade. 0 processo de transformação ocorrerá no dia do aniversário de Stanley, pelo menos na opinião de Meg, numa clara alusão ao dia do nascimento de um novo homem. Stanley, que se passeava pela casa de pijama, que não tomava banho, que não fazia a barba, que acordava tarde, que não só rejeitava as investidas de Meg, como as da jovem e atraente vizinha, Lulu, desrespeitando os valores sagrados do homem em sociedade

(designadamente, o trabalho e a virilidade masculina que nunca se diz rogada a qualquer investida feminina), o verdadeiro anti-herói, ainda tenta, apesar de tudo, num primeiro momento, resistir à ofensiva ditatorial da ordem, e da violência que sempre lhe está associada, mas como anti-herói que é, inevitavelmente, no final, sucumbe, transformado numa verdadeira marioneta, num homem sem vontade, a quem lavam, dão de beber, impecavelmente vestem e conduzem, não conseguindo apenas que fale. $\mathrm{E}$ é nesta mudez que se sente a possibilidade de alguma resistência, pequena, insignificante, talvez inútil, mas ainda assim resistência.

Jorge Silva Melo assumiu uma encenação fiel ao texto e à maior parte das indicações cénicas fornecidas por Pinter, num total respeito pelo dramaturgo que detestava que alterassem a sua obra e que proibiu Luchino Visconti de continuar as representações da sua peça Old Times, no Teatro Argentina, em Roma, uma vez que Visconti tomara a liberdade de tornar claro aos espectadores algo que era ambíguo nessa peça - que duas mulheres tinham sido

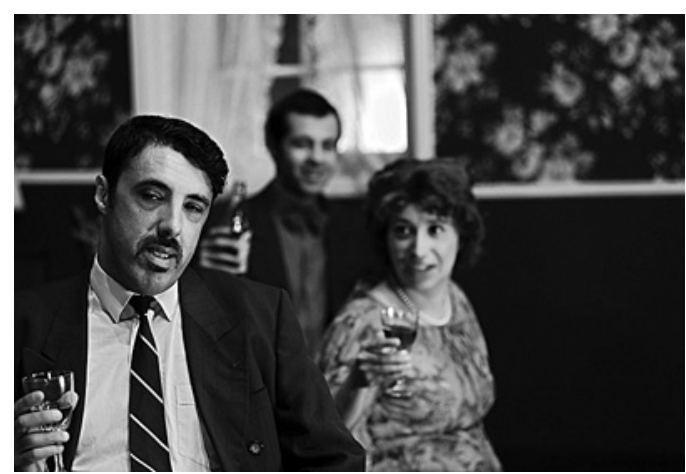

amantes na sua juventude.

Pinter foi não só dramaturgo como encenador, por isso, a sua escrita tem uma vertente prática muito acentuada, é uma escrita que nasce já para uma determinada encenação, o que dificulta, naturalmente, quem pretenda fazer uma encenação original, descontextualizada, estilizada.

A encenação de Jorge Silva Melo é, por isso, em nossa opinião, irrepreensivel, conseguindo que tudo harmonicamente se encaixe. Recorrendo a um cenário naturalista, da autoria de Rita Lopes Alves, os actores encontram-se mergulhados no interior de uma típica casa da classe média baixa inglesa nos idos anos 50.0 papel de parede às flores, a carpete puída, os cortinados, os naperons, os móveis em madeira barata, as jarras com flores de plástico, a caixa de engraxador, os azulejos coloridos da cozinha, e as inevitáveis cadeiras e mesa, objectos indispensáveis nas obras de Pinter, tudo isso nos faz remontar àquele ambiente pesado, desconfortável e feio que Pinter pretendeu retratar. Se o cenário fosse diferente, menos discreto, a mestria do texto de Pinter, a sua fina e ambígua ironia, correria o risco de se perder.

Do mesmo modo, também os figurinos, igualmente da autoria de Rita Lopes Alves, e ainda que não totalmente fiéis à época (veja-se o vestido demasiado curto de Lulu), procuram aquele ambiente, aquele momento do passado recente.

Por sua vez, totalmente fiel às indicações cénicas do autor, as luzes, da autoria de Pedro Domingos, diferem consoante seja dia, iluminado pelos projectores do tecto, dando particular incidência à zona da porta envidraçada e da janela, ou noite, iluminada pelo candeeiro de tecto, pelos candeeiros de parede e pelo candeeiro em cima do móvel e ainda com uma ténue luz dos projectores do tecto; e naturalmente actuam em total cumplicidade com o texto na noite da festa de aniversário de Sanley, com a diminuição das luzes e o foco da lanterna na cara de Stanley nos momentos do discurso de Meg e do brinde e com o total blackout quando Stanley se revolta, agarrando-se violentamente ao pescoço de Meg, procurando estrangulála e, no final dessa segunda cena, apenas com o foco da lanterna sobre o rosto aterrorizado de Stanley.

Por fim, os actores, confortáveis neste registo naturalista, contracenam, revelando um universo que, contrariando a envolvência do cenário, nada tem de datado, nem de concreto, onde tudo é possivel como só acontece na realidade, e, por isso, nos lembra o absurdo, nos perturba, nos faz questionar quem sejam essas personagens que nos fogem, sem biografia, ou pior, com várias biografias, como Goldberg, que ora é Nat ora é Simey ora é Benny.

Andreia Bento (Meg) é a sessentona dona-de-casa perfeita, meio encurvada, com um olhar perdido num

\section{$<>$ \\ Feliz aniversário, de Harold Pinter enc. Jorge Silva Melo, Artistas Unidos, 2012 (<Andreia Bento e Américo Silva > António Simão, Tiago Matias e Andreia Bento;} v Rúben Gomes e Tiago Matias), fot. Jorge Gonçalves. 


\section{$>$
Feliz aniversário, \\ de Harold Pinter, \\ enc. Jorge Silva Melo, \\ Artistas Unidos, 2012 \\ (Rúben Gomes \\ e Andreia Bento), \\ fot. Jorge Gonçalves.}

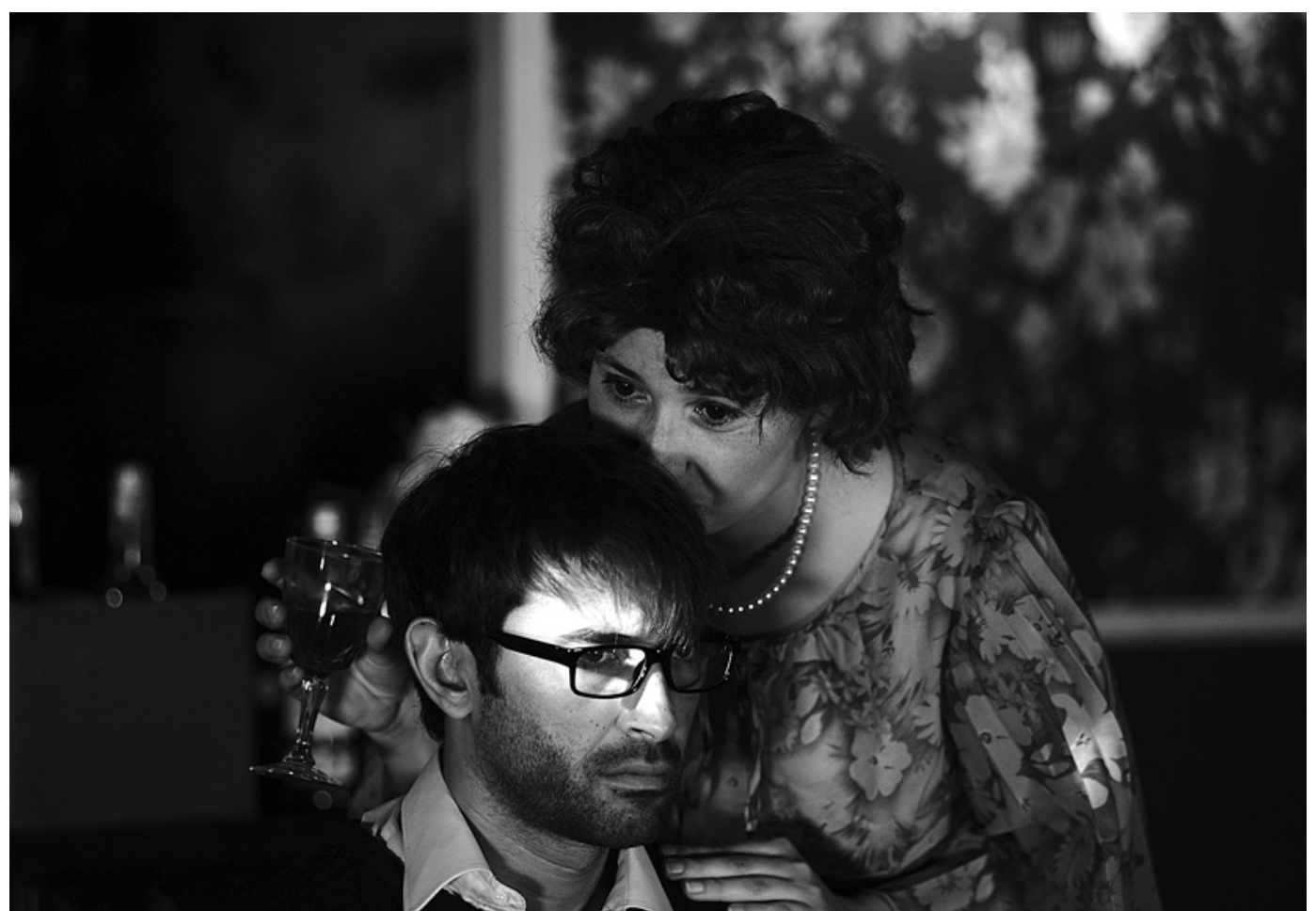

qualquer sonho de felicidade, que procura entreter o tempo falando das mais diversas trivialidades, mas que ainda mantém a vaidade feminina, essa triste e vã expectativa de ser desejada, e que vive aterrorizada perante a ideia da chegada de um carrinho-de-mão que virá, talvez, buscála. Américo Silva (Petey) é um persuasivo marido, pacato, fatigado, conformado, alheado nas suas leituras de jornal, que responde desatentamente às perguntas incessantes da mulher, mas que, apesar de tudo, é o único que compreende o que se está a passar, se preocupa e que tenta, de uma forma bondosa, opor-se à partida de Stanley,

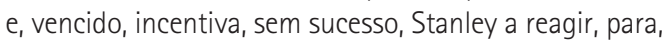
no final, à mesa com Meg, voltar à sua postura resignada. Rúben Gomes (Stanley), numa representação esmerada, trasmuda-se de jovem rebelde sem causa, caprichoso e mimado, na vítima consciente da tortura, aterrorizado e vencido, e, por fim, no boneco estereotipado, oco e mudo em que o transformaram. Alexandra Viveiros (Lulu) é uma consistente jovem, fútil e casadoira, a quem Goldberg satisfaz os seus inconfessáveis desejos eróticos. E por fim, António Simão num poderosíssimo Goldberg leva-nos à confiança e ao medo, armas terriveis de todos os manipuladores; e Tiago Matias (McCann), numa representação exemplar, lembra-nos o boneco assassino, paranóico e obsessivo, que obedece cegamente ao seu chefe.

Feliz aniversário é, sem dúvida, uma parábola do poder e do poder opressivo e violento de forças colectivas, como o são o Estado ou a Igreja, e, por isso, é uma peça de cariz fortemente político e, infelizmente, demasiado actual. Por ironia - o que apenas acontece aos grandes mestres -, quando estreou em Londres, nos anos 50, uma das críticas apontadas foi a da frivolidade, por não seguir os ventos da época tão fortemente marcada por movimentos de contestação e de compromisso político.

Em Feliz aniversário, Pinter não nos diz sobre o que fala, mostra-nos apenas, e mostra-nos, num contexto familiar, o drama da tortura física e psicológica, quer seja perpetrada nos estados totalitários comunistas ou de direita quer seja perpetrada nos campos de concentração dos Estados em guerra, quer seja perpetrada nas prisões dos Estados alegadamente civilizados, como o é a prisão de Guantánamo, pertencente à base militar norte-americana, ainda hoje em funcionamento e que viola as mais elementares leis de um Estado que se apelida de Direito.

Mas a sua actualidade não se fica por aí. No momento histórico em que vivemos, quando a legitimidade democrática cada vez mais e continuamente se perde em prol de um principio economicista abstracto, de um conceito uniformizador de redução de défice, em que os países do sul da europa são os Stanley's e notoriamente os do norte, encabeçados pela poderosa Alemanha, os Goldberg's, e os nossos políticos, sem qualquer dúvida, os McCann's, e os Petey's todos os cidadãos do sul da europa que simplesmente se alheiam, importa que os Stanley's e os Petey's arrisquem um final diverso, se unam e reajam, que gritem, em uníssono, energicamente "Eles não têm nada que nos dar ordens!".

\section{Referências bibliográficas}

AA.W. (2002), "De e sobre Harold Pinter: conversas, depoimentos, ensaios, discursos, uma entrevista", Artistas Unidos: Revista, dir. Jorge Silva Melo, Lisboa, Cotovia, n. 7 , Maio.

PINTER, Harold (2005), Teatro I, trad. Pedro Marques, Artur Ramos, Jaime Salazar Sampaio, João Saboga e Francisco Frazão, Lisboa, Relógio d'Água. -- (2006), Várias vozes, trad. Miguel Castro Caldas, João Paulo Esteves da Silva, Jorge Silva Melo, Francisco Frazão, Pedro Marques e Joana Frazão Vila Nova de Famalicão, Edições Quasi.

\section{Sitiografia}

$<w w 3 . f l . u l . p t / C E T b a s e />$

<www.rtp.pt/play/p872/e91782/estado-da-arte> 